\title{
HISTÓRIA DA CARTOGRAFIA DO RIO PEPERI-GUAÇU E A FORMAÇÃO DO ESPAÇO DO EXTREMO OESTE CATARINENSE
}

\author{
Vitor Luiz Scartazzini Bocalon \\ Universidade Federal da Fronteira Sul, Curso de Geografia, Chapecó, SC, Brasil \\ vitorboca@yahoo.com.br \\ Cristina Otsuschi \\ Universidade Federal da Fronteira Sul, Curso de Geografia, Chapecó, SC, Brasil \\ cristinaotsuschi@yahoo.com.br
}

\begin{abstract}
RESUMO
O rio Peperi-Guaçu, marco de fronteira entre Brasil e Argentina, no atual extremo oeste catarinense, teve seus primeiros registros por padres inacianos que desenvolviam trabalhos de catequização na Bacia do Prata, entre os séculos XVII e XVIII. O rio servia de caminho natural entre as bacias dos rios Iguaçu, a norte, e Uruguai, a sul e; adquiriu importância estratégica no desenvolvimento dos povos jesuítas do Guayra (atual estado do Paraná) e Sete Povos (Rio Grande do Sul). O principal objetivo foi caracterizar o rio Peperi-Guaçu com base nos mapas Paraquaria Vulgo Paraguay Cum Adjacentibus, de 1670, o Paraquaria Provinciae cum adiacentibo novíssima descriptio, de 1732, ambos de produção inaciana, bem como o Mapa dos confins do Brasil, com as terras da Coroa de Espanha na America Meridional, de 1749 e o Mappa da demarcação que por ordem de S. M. F. e C. fez no anno de 1759. A cartografia inaciana da região, serviria de fonte para a execução dos Mapas das Cortes, sobre o qual se desenhou a fronteira entre os domínios espanhol e português na Bacia do Prata. Somente no ano de 1759, o rio Peperi-Guaçu seria efetivamente cartografado conforme requisitos estabelecidos no Tratado de Madri em 1750.
\end{abstract}

Palavras-chave: Rio Peperi-Guaçu. Cartografia jesuítica. Bacia do Rio de La Plata. Fronteira.

\section{HISTORICAL CARTOGRAPHY OF THE PEPERI-GUAÇU RIVER AND THE FORMATION OF THE SPACE IN THE EXTREME WEST OF SANTA CATARINA STATE}

\begin{abstract}
The Peperi-Guaçu river, border between Brazil and Argentina, in the extreme West of Santa Catarina State, had its first records by Ignatian priests who developed catechetical work in the Rio de La Plata Basin, during the XVII and XVIII centuries. The river was a natural route between the basins of the rivers Iguaçu, to the North, and Uruguay, to the South and, acquired strategic importance in the development of the jesuit from Guayra (Paraná State) and Sete Povos (Rio Grande do Sul State). The main objective was to characterize the Peperi-Guaçu River based on the maps Paraquaria Vulgo Paraguay Cum Adjacentibus, printed in 1670, o Paraquaria Provinciae cum adiacentibo novíssima descriptio, from 1732, both of Ignatian production, as well as the Mapa dos confins do Brasil, com as terras da Coroa de Espanha na America Meridional, from 1749 and the Mappa da demarcação que por ordem de S. M. F. e C. fez no anno de 1759. The Ignatian cartography of the region, would be the source for the execution of the Maps of Cortes, on which drew the border between the Spanish and Portuguese domains in the Plata Basin. Only in the year 1759, the Peperi-Guaçu River was effectively mapped by the Segunda Partida group according to the requirements established in the Tratado de Madrid in 1750.
\end{abstract}

Keywords: Peperi-Guaçu River. Jesuit cartography. Rio de La Plata Basin. Border.

\section{INTRODUÇÃO}

A atual fronteira territorial entre Brasil e República Argentina, no extremo oeste catarinense, tem como marco o rio Peperi-Guaçu. O rio Peperi-Guaçu nasce no município de Dionísio Cerqueira e possui traçado aproximado geral norte-sul, desembocando no rio Uruguai, no município de Itapiranga. Ao

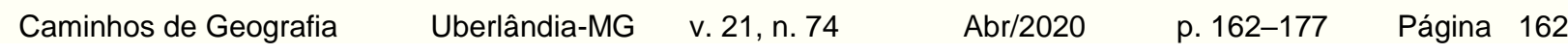


longo de seu percurso, banha municípios limítrofes com o território argentino, a saber, Dionísio Cerqueira, Princesa, Guaraciaba, Paraíso, Bandeirante, Santa Helena, Tunápolis e Itapiranga. O termo Peperi-Guaçu, de origem guarani, significa "rio de quedas grandes", em alusão às corredeiras presentes nos cursos médio e inferior do rio. O limite internacional materializado pelo rio PeperiGuaçu foi oficialmente estabelecido em 1750, por meio do tratado de Madri, em um acordo internacional firmado pelas duas potências econômicas à época, a Coroa de Castela (Espanha) e a Coroa de Portugal. O mapa utilizado para a elaboração do tratado por ambas as coroas, seria o Mapa dos confins do Brasil, com as terras da Coroa de Espanha na America Meridional, de 1749, conhecido como Mapa das Cortes.

Durante os séculos XVII e XVIII, um grande número de mapas foi confeccionado abarcando a bacia do Prata, incluindo o que é hoje o extremo oeste catarinense, local de ocorrência da bacia do rio Peperi-Guaçu. No entanto, poucos faziam menção ao referido rio. A principal produção cartográfica da América Platina, ao longo desse período, era feita por missioneiros jesuítas durante os processos de evangelização efetuados às margens dos principais rios da bacia do Prata, como os rios Paraguai, Uruguai, Paraná e Iguaçu, onde foram estabelecidas as reduções jesuíticas. A região era ocupada por diferentes etnias indígenas, principalmente os Aymaras (habitando a região norte da atual Argentina), os Guaranis (região sul do Brasil, bem como parte do Paraguai e Argentina) e Charruas (sul do Brasil e Uruguai). Tal população, indubitavelmente, auxiliaria sobremaneira as andanças dos europeus que registravam os acidentes naturais e os cursos fluviais mais significativos que seriam utilizados na confecção de mapas territoriais. Os mapas produzidos pelos jesuítas serviriam de fonte, posteriormente, para produção de globos e mapas mundiais de então, como por exemplo, "L'Amérique Meridionale ou la partie méridionale des Indes Occidentales", de Vicenzo Coronelli, em 1689, e a "Carte de L'Amérique Méridionale", de Jean Baptiste Bourgignon D'Anville, em 1748 (CINTRA e FURTADO, 2011).

Diante desse breve histórico, o objetivo do presente artigo é o de estabelecer como foi representado cartograficamente o rio Peperi-Guaçu antes e após o Tratado de Madri, de 1750, caracterizando os primeiros registros do rio em cartas geográficas desenhadas entre os séculos XVII e XVIII. Para tal fim, foram analisadas qualitativamente quatro mapas: Paraquaria Vulgo Paraguay Cum Adjacentibus, de 1670 e o Paraquaria Provinciae cum adiacentibo novíssima descriptio, de 1732, cujas fontes para a produção dos mesmos são comprovadamente inacianas; o Mapa dos confins do Brasil, com as terras da Coroa de Espanha na America Meridional, de produção portuguesa, de 1749, e por fim, o Mappa da demarcação que por ordem de S. M. F. e C. fez no anno de 1759, a seg. da partida da boca do Rio Ibicuy, seguindo o curço dos Rios Uruguay, Piriry S. Ant. Iguaçu, e Paranã c., igualmente de produção portuguesa. Tais mapas são os que efetivamente mostram o registro do rio PeperiGuaçu na produção cartográfica de então. Também foram analisados os registros do Diário das Três Partidas de Demarcação, escritos pela equipe portuguesa, concernentes à Segunda Partida, responsável pelo mapeamento do segmento fronteiriço, no qual o rio Peperi-Guaçu estava incluído.

\section{OS MAPAS JESUÍTAS E O RIO PEPERI-GUAÇU}

O estabelecimento do registro cartográfico referente ao rio Peperi-Guaçu está intimamente atrelado às peregrinações dos padres jesuítas na Bacia do Prata, durante os séculos XVII e XVIII. Os jesuítas chegaram à América do Sul em 1549, estabelecendo-se inicialmente no Brasil. No entanto, foi durante os processos de ocupação da américa espanhola, onde implantaram várias reduções, que prosperaram, pelo fato de somente a Espanha considerar os índios nativos seus súditos reais, desde que fossem catequizados. Tiveram profícua participação na formação das américas católicas (atuais América Central e América do Sul; ÁLVAREZ, 2014). Em um segundo momento, chegaram na américa francesa (atual Estados Unidos) em 1625, porém logo fracassam e retornam à Europa. $\mathrm{Na}$ américa católica austral, onde os jesuítas tiveram maior influência, deixaram legados importantes até os dias de hoje, principalmente na bacia do Prata. Os primeiros jesuítas a chegarem na região da bacia do Prata eram procedentes do Peru, em 1585, e outros do Brasil, em 1587. A partir de 1604 fundaram várias reduções jesuíticas ao longo dos principais rios da bacia do Prata. Nas margens do rio Uruguai, atual estado do Rio Grande do Sul, fundaram um total de sete reduções, compondo o território dos Sete Povos. Ao longo do rio Paraná, quinze reduções foram fundadas, compondo o território do Guayra. Ambos os territórios tinham o intuito de agregar os povos indígenas junto às 
reduções. Até 1702, chegaram a contar com trinta povos missioneiros (GONZÁLES, 2006; ÁLVAREZ, 2014).

Apesar de os mapas portugueses mencionarem o rio Peperi-Guaçu somente a partir do Mapa das Cortes, de 1749, o contrário é observado nos mapas produzidos pelos jesuítas, visto serem eles os que efetivamente peregrinaram pelas terras hoje consideradas porções fronteiriças entre Brasil e Argentina. A designação "Rio Pepiry" surgiria nos mapas elaborados pelos jesuítas ao longo de várias expedições cujos objetivos eram, dentre outros, estabelecer as dimensões e a morfologia dos rios pertencentes à bacia do Prata. A manutenção do nome indígena se coaduna com uma das características mais marcantes da atuação da Companhia de Jesus, que consistiu em inserir na sua ação pastoral a cultura indígena local. Para isso, conforme Alcalá (2014), "pegavam destes tudo aquilo que pudesse auxiliar nos processos de evangelização" (ALCALÁ, 2002, p. 5). Para a região que hoje abarca o extremo oeste catarinense, as designações tupi-guarani para rios ou outras feições geográficas dignas de registros foram mantidas pelos jesuítas nos vários mapas por eles produzidos entre os séculos XVII e XVIII (FURLONG, 1936). Mesmo tendo conservado as denominações tupisguaranis, a grafia mostrou variação ao longo do tempo, como o caso do rio Uruguai, inicialmente registrado como "Ruruguay", e mesmo o rio Peperi-Guaçu, grafado por vezes, como "Rio Piquiri", "Pequiri", "Pepiti" ou "Pipiry".

Por serem os personagens que efetivamente ocuparam e se inseriram na paisagem platina, os jesuítas deixaram extenso legado cartográfico, registro das andanças efetuadas na região (FURLONG, 1936). Os dados descritos e registrados foram utilizados por renomados cartógrafos europeus para a confecção de mapas sobre o novo continente que estava recém sendo caracterizado. É o caso do mapa Paraguay, o Prov. de Rio de la Plata: cum regionibus adiacentibus, Tvcvman et Sta. Cruz de la Sierra, elaborado provavelmente em 1600, por Jodocus Hondius, em Amsterdã. Os primeiros mapas produzidos no início das explorações na América do Sul possuíam características das denominadas "cartas portulanas" ${ }^{1}$, ou seja, cartas específicas para navegação em que era registrada a linha de costa da área navegada, as feições geográficas mais marcantes e a localização das principais cidades e portos situados na costa. No entanto, com as informações advindas, principalmente das observações jesuíticas, os mapas produzidos para a porção sul do continente americano passariam a apresentar características mistas, tanto de cartas portulanas quanto de mapas geográficos, como o caso do mapa de Jodocus Hondius (GOLIN, 2011; FARINA e OLIVEIRA, 2016).

O resultado das peregrinações dos jesuítas foi ampla documentação cartográfica pela região da bacia do Prata, conforme atesta Furlong (1936). A partir de Assunção, atual Paraguai, em 1609, os jesuítas iniciaram os processos de catequização dos índios, incursionando território adentro em quatro direções distintas da bacia do Prata: pelos rios Paraná e Paraguai, Itatim, atual sul do Amazonas, bem como Guairá e Tape, estas duas últimas na porção oeste dos atuais estados do Paraná, Santa Catarina e Rio Grande do Sul (MAEDER, 1999; XAVIER, 2011). Não existem relatos específicos sobre a passagem dos jesuítas pela região do extremo oeste catarinense. É a profícua documentação cartográfica produzida pelos jesuítas durante suas peregrinações, englobando a área onde atualmente se encontra o extremo oeste catarinense, que efetivamente atesta, como testemunho documental único, a passagem dos mesmos pela região (FURLONG, 1936; BARCELOS, 2010).

Durante a peregrinação dos jesuítas, várias anotações foram sendo feitas e reportadas nas denominadas Cartas Ânuas² (FANTIN, 2010; ARANHA, 2014). As impressões eram transmitidas para os croquis e esboços que tentavam representar o espaço. Estes traços iniciais serviriam de base para a execução dos mapas Paraquaria, vulgo Paraguay, cum adjacentibus, de 1670, e do Paraquaria Provinciae cum adiacentibo novíssima descriptio, de 1732. Apesar de ambos os mapas

\footnotetext{
${ }^{1}$ Cartas Portulanas: na definição de Oliveira (1983), eram mapas que continham informações sobre distâncias e linhas de rumo, a partir de um ponto de origem central. Não apresentavam graduações relativas a latitudes e a longitudes, apenas escalas em milhas italianas.

2 Cartas Ânuas: conforme Berto (2011), eram informes regulares que enviavam os Padres Provinciais do Paraguai ao General da Companhia de Jesus, que residia em Roma.
}

$\begin{array}{lllll}\text { Caminhos de Geografia } & \text { Uberlândia-MG } & \text { v. 21, n. } 74 & \text { Abr/2020 } & \text { p. 162-177 Página } 164\end{array}$


representarem a Província Jesuítica do Paraguai, em nenhum deles foram traçados os limites territoriais entre as partes pertencentes à Espanha ou à Portugal. No entanto, era informalmente tido como território jesuíta a bacia do Prata, inserida, por sua vez, em território espanhol. Os jesuítas consideravam os limites vigentes à época como sendo: a leste, a linha estabelecida pelo Tratado de Tordesilhas; a norte, a "Laguna de Xarayes" (atual Pantanal Mato-grossense); a oeste, a cadeia andina; e a sul, a desembocadura do rio da Prata (FURLONG, 1936; COSTA, 2007; XAVIER, 2011).

Somente a partir do Mapa das Cortes, efetuado em 1749 e utilizado no Tratado de Madri, em 1750, as questões territoriais no que hoje é o extremo-oeste catarinense seriam estabelecidas e representadas em mapas. A fronteira estabelecida à época do Tratado de Madri estaria inserida no conceito de "fronteira linear" (MACHADO, 2000; FERRARI, 2014), conceito comum durante a época das grandes navegações, quando os estados europeus estavam estabelecendo seus limites fronteiriços. "Fronteira linear" compreende um dos primeiros conceitos da Geografia moderna, quando se estabelecem, nos mapas, as representações precisas de limites territoriais através da linearização (FERRARI, 2014). Após serem estabelecidos, via Tratado de Madri, os limites territoriais no atual extremo oeste catarinense, Portugal procurou modernizar - via contratação de técnicos e compra de equipamentos modernos à época -, suas escolas e universidades, a fim de poder realizar expedições de reconhecimentos na região, para que se estabelecessem as linhas fronteiriças entre os territórios de ambas as coroas (FERREIRA, 2007; MORAN, 2009).

\title{
O TRATADO DE MADRI (1750) E A CITAÇÃO AO RIO PEPERI-GUAÇU
}

Durante os séculos XVII e XVIII, Portugal e Espanha se mostravam como potências hegemônicas, procurando, cada uma à sua maneira, tomar posse das novas terras que estavam sendo descobertas por meio das grandes navegações. A disputa, incrementada com a descoberta da América por Cristóvão Colombo, em 1492, abria espaço para novas contendas territoriais. O Tratado de Tordesilhas, firmado entre Portugal e Espanha, em 1494, teria sido o primeiro tratado internacional com o intuito de estabelecer os processos de ocupação territorial de terras recém descobertas e que viriam a ser descobertas. O tratado estabelecia que todas as terras descobertas ou que viriam a ser descobertas a oeste do Meridiano de Tordesilhas seriam possessões espanholas e aquelas a leste, portuguesas. O Meridiano de Tordesilhas ficaria estabelecido como sendo aquele situado a 370 léguas à oeste da Ilha de Santo Antão, a mais ocidental do Arquipélago dos Açores. Devido às dificuldades técnicas em se estabelecer a real posição do Meridiano de Tordesilhas, além do fato de Portugal questionar o seu prolongamento no hemisfério oposto, e assim, manter a disputa territorial sobre as Filipinas e demais territórios asiáticos, o tratado pouco efeito prático teve. Soma-se a isso o fato de novas terras estarem sendo descobertas naquele período, incluindo-se aí as terras da porção meridional da América do Sul, principalmente aquelas relacionadas à bacia do Prata.

Com o passar dos anos, assim, fazia-se necessário um novo tratado que estabelecesse as reais fronteiras entre as duas coroas na América do Sul. O Tratado de Madri, firmado em 1750, estabeleceu grande parte da fronteira brasileira, já citando o rio Peperi-Guaçu como o limite entre terras portuguesas e espanholas, conforme estabelecido no Artigo $\mathrm{V}$ do referido documento.

\begin{abstract}
Subirá desde a boca do Ibicuí pelo álveo do Uruguai, até encontrar o do rio Peipiri ou Pequiri, que deságua na margem ocidental do Uruguai; e continuará pelo álveo do Pepiri acima, até a sua origem principal; desde a qual prosseguirá pelo mais alto do terreno até a cabeceira principal do rio mais vizinho, que desemboque no rio Grande de Curitiba, por outro nome chamado Iguaçu. Pelo álveo do dito rio mais vizinho da origem do Pepiri, e depois pelo do Iguaçu, ou rio Grande de Curitiba, continuará a raia até onde o mesmo lguaçu desemboca na margem oriental do Paraná; e desde esta boca prosseguirá pelo álveo do Paraná acima; até onde se lhe ajunta o rio Igurei pela sua margem ocidental' (SOUSA, 1939, p. 4)
\end{abstract}

Tanto Portugal quanto Espanha apresentaram uma série de documentos para que pudessem ser estabelecidos os limites fronteiriços entre as novas possessões no entorno do Prata. Portugal se 
baseou no Mapa dos confins do Brasil com as terras da coroa de Espanha na América Meridional, concluído em 1749. Esse mapa cartográfico também foi aceito como documento oficial para delimitação das terras. No entanto, para a elaboração do traçado austral do limite, grande parte das informações foram advindas dos levantamentos pretéritos na área feitos pelos jesuítas, e apresentadas nos mapas Paraquaria e Paraquaria cum adiacentibus. O rio Peperi-Guaçu, grafado na carta como Pequeri, foi representado como sendo um curso d'água menor em relação aos mapas anteriores, além de possuir traçado desde a nascente até o curso médio, com direção leste-oeste, e a partir do curso médio até a desembocadura no rio Uruguai, com traçado norte-sul. Além desse erro, vários outros seriam detectados em trabalhos de cartografia do rio, conforme se comentará mais adiante.

Um dos problemas relacionados à execução dos artigos estabelecidos no Tratado de Madri era a má vontade, por parte dos portugueses, em se demarcar efetivamente o rio Peperi-Guaçu como limite fronteiriço estabelecido no Tratado de Madri. Uma das razões se referia ao fato de Portugal querer acesso à navegação pelos rios da bacia do Prata, algo que interferiria na soberania espanhola sobre a região. Esse acesso também facilitaria o aprisionamento de índios por parte dos portugueses, principalmente aqueles situados nas reduções jesuíticas da Banda Oriental, atual Rio Grande do Sul (SEGARRA, 1969; FERREIRA, 2007).

Apesar de inicialmente o Tratado de Madri ser aceito por ambas as coroas, em 1761, a Espanha rompe o tratado e intensos conflitos se instalam nas regiões fronteiriças do Prata, principalmente na Banda Oriental do Uruguai. Porém, novas tratativas diplomáticas iniciam-se para que outro tratado seja logo assinado, que seria o Tratado de Santo Ildefonso, de 1777 (ALMEIDA, 2005; CHAVES, 2014).

\section{O PARAQUARIA}

O mapa Paraquaria Vulgo Paraguay Cum Adjacentibus constitui-se em um mapa sintético, mostrando uma seção da América Latina entre Rio de Janeiro e Buenos Aires (Figura 1). A autoria do mapa é de Jean Blaeu, por solicitação de Gerard Coeck, e foi publicado em 1670, com posteriores reedições coloridas. As fontes utilizadas para a execução do mapa até hoje são imprecisas, porém, acredita-se que foram utilizados mapas prévios, efetuados por missioneiros jesuítas nesse período (FURLONG, 1936). Isso, por estar ressaltado, em sua porção inferior, selo de dedicatória ao Padre inaciano Vicentio Carrafa. A divulgação do mapa Paraquaria se deu mediante a obra de divulgação científica "De Neuwe en Onbekende Weereld", publicada em 1671, por Arnoldus Montanus, importante escritor holandês do século XVII.

O mapa, de dimensões de $45 \mathrm{~cm}$ por $56 \mathrm{~cm}$, apresenta coloração sépia uniforme, não sendo indicado o meridiano de origem. A projeção cartográfica não está especificada, levando-se a crer ser carta plano quadrática, comum nos mapas da época. Não apresenta escala, porém mostra legenda (notularum explicatio) em um cartucho situado junto à margem inferior esquerda.

De forma imprecisa, o mapa marca características do relevo pela representação gráfica de pequenos morros. É possível identificar, ao longo dos principais rios mapeados, linhas pontilhadas, correspondentes aos caminhos efetuados pelos jesuítas durante os processos de implantação das reduções. Algumas outras curiosidades apresenta o mapa, como, por exemplo, o Oceano Atlântico, identificado como Mar del Norte, e as regiões densamente florestadas são representadas por pequenos ícones que remetem a árvores. Os topônimos são grafados em latim ou mantidas as denominações nativas indígenas. 
Figura 1 - Visão geral do Mapa Paraquaria Vulgo Paraguay Cum Adjacentibus e destaque do rio "Pepiri".

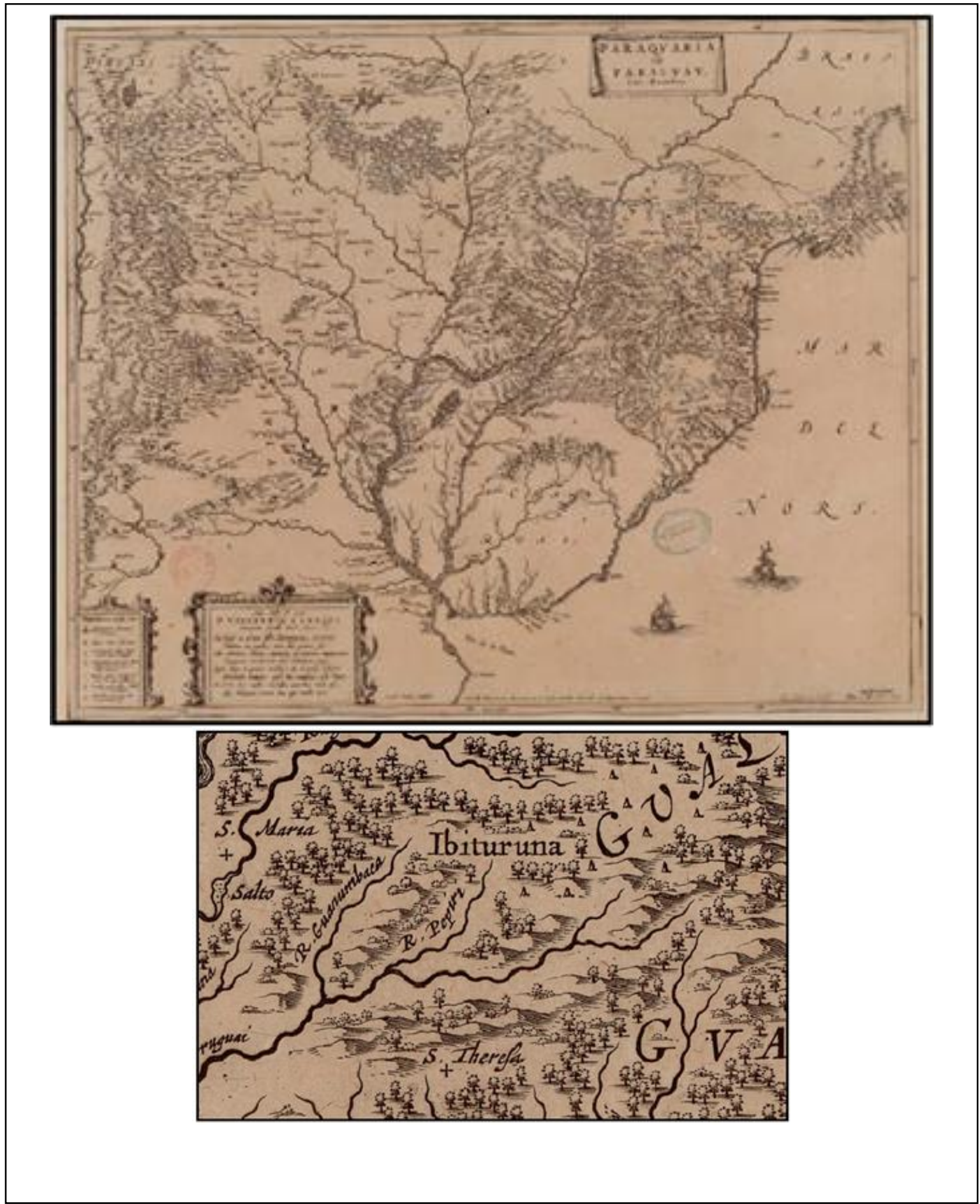

Fonte - Biblioteca digital luso-brasileira, 2018.

O rio Peperi-Guaçu encontra-se grafado como "Pepiry", sendo representado com afluente do rio Uruguai (grafia essa apresentada no mapa) a montante do rio Guanumbaca. O rio Peperi-Guaçu, ainda, é representado com pouca sinuosidade e com acentuada direção nordeste-sudoeste, sendo sua nascente localizada em região identificada como "Ibituruna", pertencente a outra maior, denominada de "Gualachos". A região referida como Ibituruna encontra-se no atual estado do Paraná, e englobava as missões jesuíticas lá estabelecidas. O termo "Gualacho", por sua vez, reporta às tribos indígenas que habitavam próximas ao rio Iguaçu.

$\begin{array}{lllll}\text { Caminhos de Geografia } & \text { Uberlândia-MG } & \text { v. 21, n. } 74 & \text { Abr/2020 } & \text { p. 162-177 Página } 167\end{array}$




\section{O PARAQUARIA CUM ADIACENTIBO}

Este mapa, denominado de Paraquaria Provinciae cum adiacentibo novíssima descriptio (Figura 2), mais completo em relação ao anterior, teve como autor Joannes Petroschi, importante cartógrafo do século XVIII, e foi publicado em Veneza, no ano de 1732.

Figura 2 - Paraquaria Provinciae cum adiacentibo novíssima descriptio, em destaque o rio "Pepiry".

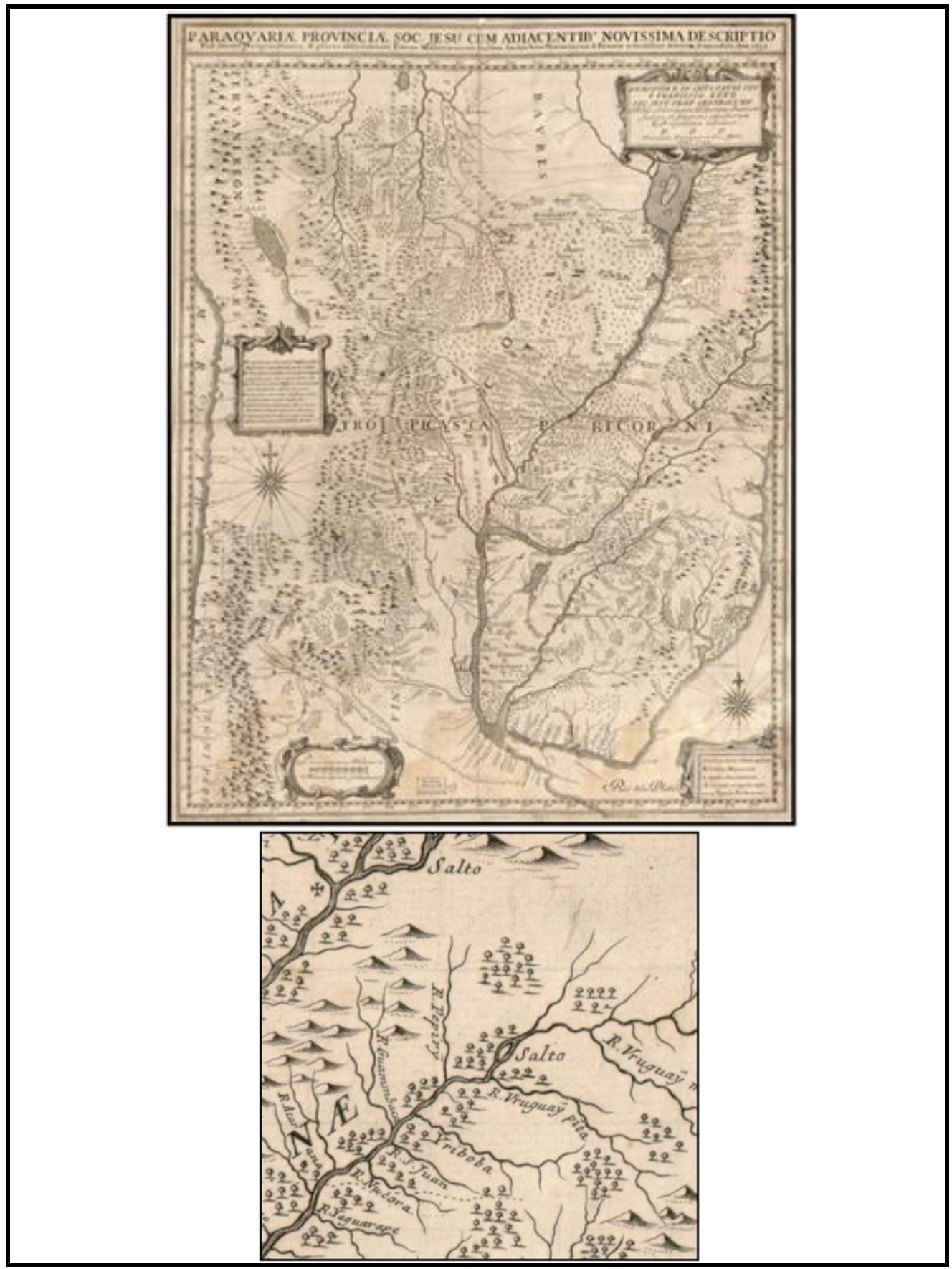

Fonte - Biblioteca digital luso-brasileira, 2018.

Edições posteriores do mapa indicam, na porção inferior, que o mesmo foi "Dressée par les Missionaires de la Compagnie de Jésus de la province du Paraguay. Publiée à Rome en 1732, et dédiée au Général de la dite Compagnie le R.P. François Retz", isto é, "Desenhado por missionários 
da Companhia de Jesus da Província do Paraguay. Publicado em Roma, em 1732, e dedicado ao General da dita Companhia, R.P. François Retz (tradução nossa)". O mapa apresenta dimensões de 78 por $56 \mathrm{~cm}$ e foi impresso em duas folhas.

Ele abrange maior área que o mapa anterior, o Paraquaria, desde Cuzco até a desembocadura do rio da Prata, e dos Andes até o Atlântico. Não estão indicados o meridiano de origem, nem a projeção cartográfica utilizada, embora as notações laterais indiquem ser uma carta plano quadrática. Apresenta escala ("Minuta Duorum Graduum") em milhas hispânicas que, convertida em escala atual, seria de 1:2.000.000. Um cartucho, situado na porção superior direita, indica a dedicatória ao Padre inaciano Francisco Retz, enquanto que outro, na porção inferior direita, mostra a legenda ("Notularum huius tabulae explicatio"). Na margem esquerda, na porção mediana da altura do mapa, outro cartucho mencionando "serem as terras desenhadas no mapa ricas em rios caudalosos e habitadas por gentes a serem convertidas e que para serem povoadas serão exigidos esforços muitos grandes por parte da Espanha (tradução nossa)". Além disso, foram desenhadas duas rosas-dos-ventos, uma logo abaixo do cartucho anteriormente referido, e outra na porção inferior direita, na altura do litoral uruguaio.

O mapa apresenta cor salmão em tom único, com frisos laterais em amarelo. Os topônimos são grafados em latim ou mantidas as denominações nativas indígenas. O rio Peperi-Guaçu, situado entre os rios Yriboba, a jusante, e Uruguay Pita, a montante, está grafado como "R. Pepiry" e o traçado do mesmo está com direção norte-sul, com pouca sinuosidade.

\section{O MAPA DAS CORTES}

O mapa das Cortes, cuja designação completa é Mapa dos confins do Brasil, com as terras da Coroa de Espanha na America Meridional (Figura 3) consiste em um mapa síntese, originalmente desenhado em Lisboa, no ano de 1749, apresentando as dimensões de $60 \times 51 \mathrm{~cm}$. Embora não conste o nome do autor ou do desenhista, foi elaborado sob a orientação de Alexandre de Gusmão, importante diplomata que influenciaria sobremaneira, a favor de Portugal, no Tratado de Madri, em 1750. O Mapa das Cortes possui várias versões pelo fato de serem feitas duas cópias idênticas, uma doada para a Espanha e outra permanecendo em Portugal, e que, a partir das quais, até o ano de 1751, outras seis cópias seriam feitas, trocadas entre as duas coroas (CINTRA, 2012).

O mapa foi confeccionado baseado em diferentes fontes. Para a região do Brasil meridional, utilizouse a carta do Padre Diego Soares, enquanto que para as terras espanholas, a carta de D'Anville, de 1733, traçada sobre os mapas originalmente desenhados pelos padres jesuítas da bacia do Prata (RIO-BRANCO, 2010). Não apresenta escala e nem o tipo de projeção utilizada, embora, aparentemente, seja uma carta plano quadrada. Não é possível a identificação do meridiano de origem, mas provavelmente tenha sido o Meridiano de Paris o mais comum utilizado então (CINTRA, 2012).

Esse mapa cartográfico apresenta coloração sépia em diferentes tonalidades, as mais escuras marcando o litoral atlântico da América do Sul e os rios de linhas duplas. Os limites territoriais são marcados por uma linha vermelha e aguados em amarelo e rosa, indicando as áreas ocupadas por portugueses e espanhóis, respectivamente. O norte é indicado por duas rosas-dos-ventos desenhadas, uma acima da baía de São Luis, no Maranhão, e outra na altura de Paranaguá, Paraná.

O mapa não apresenta legenda, embora se utilize de inúmeras simbologias, tais como desenhos de montanhas em perspectiva para caracterizar áreas com declividades acentuadas, pequenas lagoas para indicar terrenos alagados, árvores desenhadas em conjunto para indicar região densamente florestada etc. Outros símbolos são empregados, tais como pequenos círculos, indicando povoações. Eles são encimados por pequenas bandeiras, indicam fortificações, e por cruzes, sinalizam igrejas ou 
reduções jesuíticas. No lado espanhol, os topônimos são grafados em espanhol, enquanto que no lado de Portugal, em português.

Figura 3 - Mapa dos confins do Brasil, com as terras da Coroa de Espanha na America Meridional, 1749. Acima, visão geral do mapa; abaixo, detalhe mostrando o rio "Pequeri".

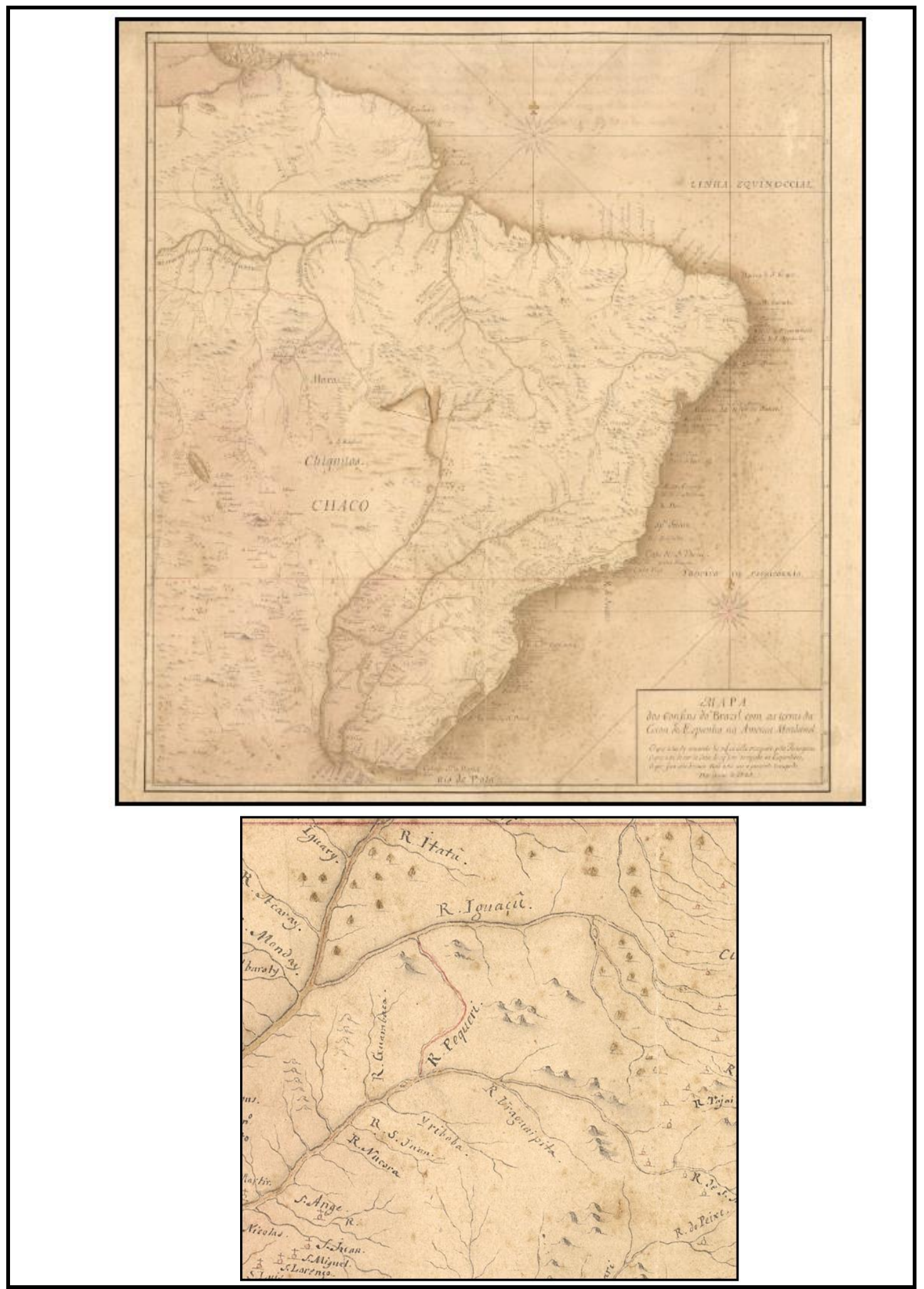

Fonte - Biblioteca digital luso-brasileira, 2018. 
Nesse mapa, o rio Peperi-Guaçu está grafado como "rio Pequeri", e traçado com baixa sinuosidade, situado entre os rios Yriboba, a jusante, e Uruguay Pita, a montante. De sua nascente até o curso médio, apresenta direção nordeste-sudoeste. A partir do curso médio até desembocar no rio Uruguai, possui direção norte-sul. Sobre o rio Peperi-Guaçu foi traçado uma linha vermelha que, em nota explicativa, no verso do mapa, deveria ser o local a ser conferido geograficamente por equipes de ambas as cortes:

\begin{abstract}
"Essa carta geográfica que há de ficar no Real Archivo de Espanha como outra semelhante q'há de ficar no Archivo Real de Portugal a há de se quem se servio o Ministro Plenipotenciario de S. M. Catolica para ajustar o tratado da divizam dos limites na America Meridional assinado em 13 de janeiro de 1750 , e por que na dita se traça huma linha vermelha que assinala e passa pelos lugares por onde se há de fazer a demarcaçam; se declara que a dita linha so serve emquanto ela se conforma com o tratado referido, e paraque a todo o sempre assim conste, nos abaixo assinados ministros plenipotenciários de S. M. F., es M. C. Ihe pusemos as nossas firmas e celos de nossas armas." (Mapa das Côrtes, 1749).
\end{abstract}

\title{
O MAPA DA DEMARCAÇÃO
}

O Mapa da Demarcação, ou Mappa da demarcação que por ordem de S. M. F. e C. fez no anno de 1759, a seg. da partida da boca do Rio Ibicuy, seguindo o curço dos Rios Uruguay, Piriry S. Ant Iguaçu, e Paranã c. (Figura 4), foi elaborado por integrantes da Segunda Partida Demarcatória, estando nominado Manuel Pacheco Christo como autor. Foi publicado em 1760, e possui dimensões de $45 \mathrm{~cm}$ por $23 \mathrm{~cm}$. Pode ser definido como mapa de referência, uma vez que visa o registro dos limites dos territórios pertencentes às coroas de Espanha e Portugal.

O mapa abrange área desde a desembocadura do rio Piquiry, no rio Paraná, a norte, até o rio Ibucuí, a sul. Possui coloração sépia, e os componentes cartográficos estão representados em coloração cinza escura. Ele apresenta escala em milhas francesas, equivalente à escala aproximada de 1:1.300.000. A legenda se resume a três símbolos: igreja estilizada representando povoações, círculo encimado por uma cruz, simbolizando igrejas, e uma barraca estilizada, indicando fortificações. Uma rosa-dos-ventos foi desenhada, localizada à margem esquerda do rio Paraná, sobre território paraguaio. Aparentemente, esse mapa se constitua em carta plano quadrada, sem identificação do meridiano de origem.

As indicações relacionadas à topografia são feitas ao longo dos maiores rios registrados na área de atuação da Segunda Partida. Para tanto, utilizou-se da técnica gráfica de morros sombreados, em que estão marcados os principais morros ao longo dos rios Ibicuí, ljuí, Uruguai, Paraná e Iguaçu, ficando o restante da carta sem indicações topográficas.

O rio Peperi-Guaçu, grafado como Pipiry Guaçú, tem pela primeira vez o seu traçado elaborado de forma mais precisa, assemelhando-se muito com o traçado de mapas atuais. Está desenhado entre os rios Jaboty, a jusante, e Apítereby, a montante. Observando-se o mapa, é possível subdividir o rio, de acordo com a direção de seu eixo principal, em quatro setores: o primeiro, no curso alto do rio, apresenta direção NE-SW, de baixa sinuosidade, recebendo dois afluentes, sem denominação, na sua margem esquerda. $O$ segundo setor, também com direção NE-SW, com média sinuosidade, também recebe dois afluentes, sem denominação, porém na sua margem direita.

O terceiro setor, com direção NW-SE, com média sinuosidade, foi cartografado com três afluentes, dois menores, e um terceiro, entre os dois anteriores, maior e denominado Pipiry Mini, atual rio das Flores. O quarto setor, desembocando no rio Uruguai, com direção NE-SW, compreende o trecho mais largo e mais sinuoso, com meandros bem ressaltados, e sem afluentes. Nesse setor, não está representado o conjunto de rochas presentes em sua desembocadura e que, conforme as informações obtidas pelos demarcadores, seria preponderante na indicação do mesmo. 
Figura 4 - Mappa da demarcação de S. M. F. e C. no anno de 1759, a seg.da partida da boca do Rio Ibicuy, seguindo o curço dos Rios Uruguay, Piriry S. Ant Iguaçu, e Paranã c. destacando o rio "Pipiry".

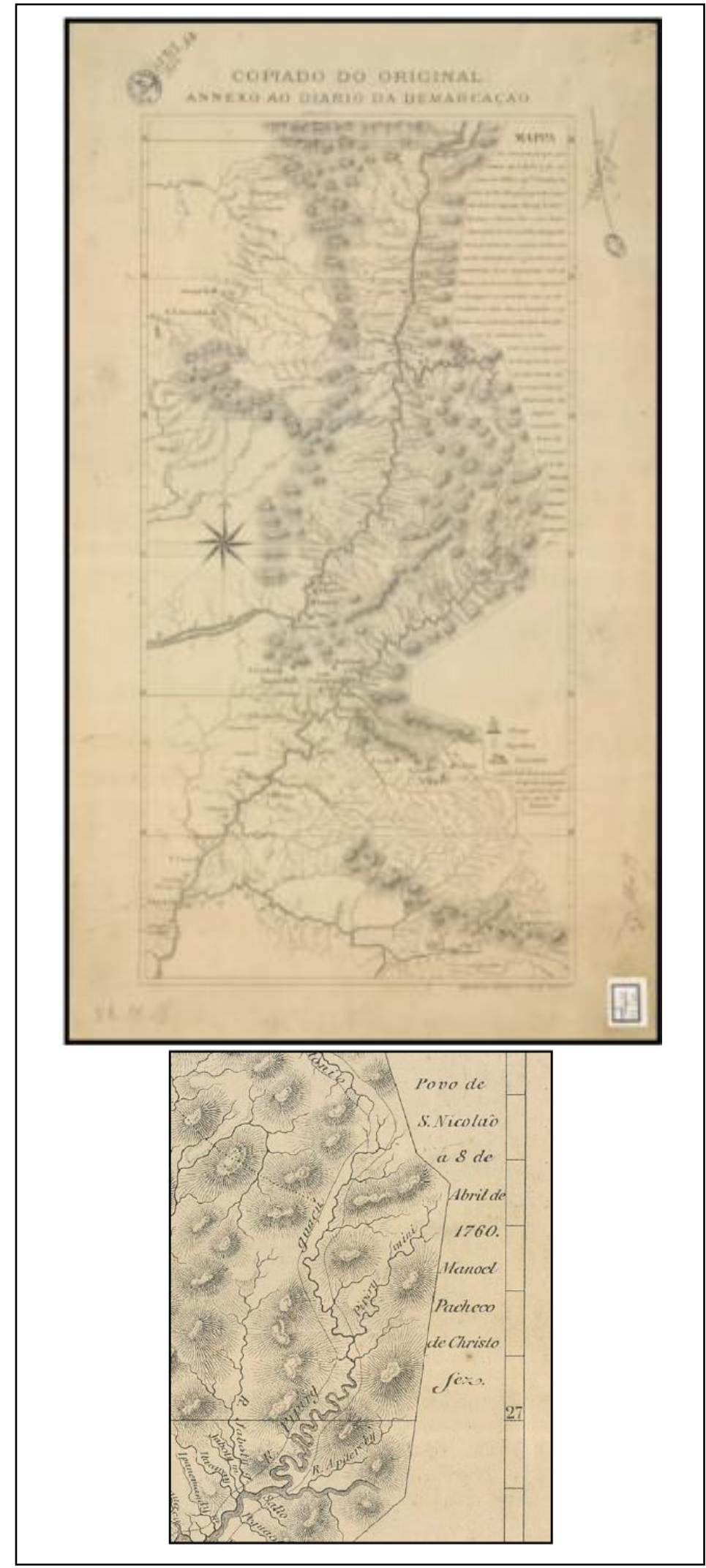

Fonte - Biblioteca digital luso-brasileira, 2018. 
Ao contrário dos mapas anteriores, esse não apresenta detalhes gráficos, como cartuchos ou mesmo outros desenhos mitológicos. Restringe-se apenas ao traçado dos rios mapeados, às representações gráficas da topografia, e ao texto explicativo em sua borda direita.

\section{A SEGUNDA PARTIDA E A CARTOGRAFIA DO RIO PEPERI-GUAÇU}

Conforme estipulado nos artigos XI e XXII do Tratado de Madri, as demarcações de fronteiras territoriais deveriam ser feitas por equipes técnicas de ambos os países, percorrendo os limites determinados pelo Tratado de Madri, e principalmente, onde as questões e as dúvidas ainda estavam pouco esclarecidas (COSTA, 2009). Para tal fim, foram estabelecidas, em 1751, duas comissões por parte de cada coroa, com igual número de participantes: a Comissão do Norte tinha o objetivo de cartografar as bacias do Amazonas e Orinoco; a Comissão do Sul visava o mapeamento da bacia do Prata (CAPDEVILA, 2016). Nas comissões constavam a participação de geógrafos, cosmógrafos, militares, capelães, além de operários e remadores, bem como índios para auxiliarem no deslocamento nas áreas mais densamente florestadas. Esse item do artigo teve como fonte os diários da Segunda Partida, contidos na Colleção de Historia e Geografia das nações ultramarinas que vivem nos domínios portugueses ou Ihes são vizinhas, tomo VII, publicada pela Real Academia de Ciências de Lisboa, em 1841.

A Comissão do Sul era chefiada por Gomes Freire de Andrada, por parte de Portugal, e Gaspar Munive de Espinosa, por parte de Espanha, ela foi dividida em três subcomissões, denominadas de Partidas Demarcadoras. Cada uma estaria encarregada de demarcar e mapear as linhas fronteiriças em segmentos específicos entre Castillo Grande (atual Uruguai) até o rio Jauru (atual Mato Grosso). A Primeira Partida, comandada por Angelo Blasco (Portugal) e Juan de Echeverría (Espanha), demarcaria a fronteira entre Castillos Grandes até a desembocadura do rio Ibicui, no rio Uruguai. A Segunda Partida, sob os comandos de José Fernandes Pinto Alpoym (Portugal) e Francisco de Agredas (Espanha), ficaria incumbida de traçar a fronteira desde a desembocadura rio lbicui, no rio Uruguai, até o Salto Grande do Paraná. Já a Terceira Partida, comandada por José Custodio de Sá e Faria (Portugal) e Manuel de Flores (Espanha), demarcaria o trecho entre o Salto Grande do Paraná até o rio Jauru (SOUSA, 1939; MARTíN-MERAS 2007).

A Segunda Partida estava composta por um geógrafo de cada coroa, cada um inserido em uma equipe de 122 pessoas por parte de Portugal e 116 por parte da Espanha. A maioria dos participantes das equipes era composta por militares e marinheiros, visto que grande parte do trajeto seria feito por vias fluviais. Além de equipamentos geodésicos, cada equipe contava com uma cópia do Mapa das Cortes, que serviu de base para o estabelecimento das fronteiras entre as coroas portuguesa e espanhola conforme o Tratado de Madri. Apesar de as equipes serem estabelecidas no ano de 1751, somente no ano de 1759, as equipes demarcatórias da Segunda Partida conseguiram se organizar para, efetivamente, iniciarem os trabalhos de cartografia (ANGELIZ, 1836; ACADEMIA REAL DAS SCIÊNCIAS, 1841).

Foi saindo de São Francisco Xavier, atual município de Porto Xavier, no estado do Rio Grande do Sul, que a Segunda Partida iniciou seus trabalhos de demarcação ao longo do rio Uruguai no dia primeiro de fevereiro de 1759. Por ser o Uruguai um rio largo e facilmente navegável em grande parte de seu percurso, sem maiores sobressaltos, a equipe conseguiu efetuar os trabalhos, até que no dia 5 de março do mesmo ano, ela chega na desembocadura do rio Peperi-Guaçu (ANGELIZ, 1836).

A chegada à desembocadura do rio coincidiu com o término de longa estiagem que assolava a região, pois, conforme os relatos dos diários, grande parte dos rios percorridos e mapeados estavam com seus níveis mais baixos que o normal, expondo pequenas barras que foram mapeadas, porém não constantes nas cartografias atuais. $O$ fato de o rio Peperi-Guaçu estar com sua vazão muito abaixo do normal dificultou seu reconhecimento imediato, visto que, de acordo com as fontes dos técnicos das partidas, o rio deveria apresentar grande volume de água e relativa correnteza (ANGELIZ, 1836; SOUSA, 1939).

A dúvida ainda se fez maior pelo fato de a principal fonte documental utilizada pelos expedicionários, que era o Mapa das Cortes, apresentar informações erradas. De fato, três informações equivocadas constantes no referido mapa são seguidamente citadas nos diários das equipes de demarcação. A primeira se referia às coordenadas geográficas da desembocadura do rio. Elas foram calculadas com base no Mapa das Cortes e não coincidiam com aquelas que estavam sendo obtidas diretamente em campo pelos geógrafos e pelos cosmógrafos de ambas as equipes. A segunda estava relacionada à real posição da desembocadura do rio. No Mapa da Cortes, a desembocadura do rio Peperi-Guaçu foi representada como estando a jusante da desembocadura do rio Uruguai-Pitá (atual rio da Várzea), o 
que na verdade estaria a montante do mesmo, conforme constatado pelas equipes demarcatórias. A terceira dizia respeito ao próprio nome do rio. Enquanto que no Mapa das Cortes o mesmo era grafado como Pequeri, nos artigos referentes ao Tratado de Madri era grafado como Pepiri. No diário, os demarcadores optam pelo nome de rio Pepiry, a fim de evitar confusões com outro rio Pequiri, homônimo, afluente do rio Paraná (ACADEMIA REAL DAS SCIÊNCIAS, 1841).

A confirmação de estarem, de fato, na desembocadura do rio Peperi-Guaçu foi atestada por um índio missioneiro, que estava no local no momento da chegada das partidas portuguesas e espanholas. Seu nome era Francisco Xavier Arirapĩ, cacique de um grupo indígena guarani, aldeado na redução de São Francisco Xavier. Pouco registro documental existe sobre esse personagem histórico, mas sua presença no local teria sido de suma importância para que fossem dirimidas quaisquer dúvidas existentes sobre o rio Peperi-Guaçu. De acordo com seu testemunho, aquela não teria sido a primeira vez que tropeava gado seguindo o rio Peperi-Guaçu, desde a redução de São Francisco Xavier até o ponto que os indígenas denominavam de Espia. Ao contrário, segundo depoimento do índio, várias vezes ele o teria feito, e não somente ele, mas outros de seu povo também. De acordo com relatos históricos, Espia era um ponto de observação erigido pelos jesuítas, na porção ocidental do rio, próximo aos afluentes Jaboti ou Pepiri-Mini, e que servia para observar a chegada dos bandeirantes paulistas (TAUNAY, 1951; PEREIRA, 2012). Com as dúvidas dirimidas, em comum acordo de ambas as equipes da Segunda Partida e na presença da testemunha Francisco Xavier Arirapĩ, no dia 8 de março de 1759, foi lavrado o Ato de Reconhecimento da desembocadura do rio Peperi-Guaçu (ANGELIZ, 1836; ACADEMIA REAL DAS SCIÊNCIAS, 1841).

Durante os trabalhos de demarcação, as equipes portuguesas e espanholas perceberam sinais de que a área mapeada não era totalmente isolada. Além do relato do índio Francisco Xavier Arirapĩ de que o local era passagem de tropas de gados missioneiros, as equipes também se deparavam com sinais de ocupação provisória na região, como a presença de roças indígenas abandonadas às margens do rio, e a presença de objetos deixados por bandeirantes paulistas, tais como facas, pilóes e sinais de fogueiras de acampamentos (ANGELIZ, 1836; ACADEMIA REAL DAS SCIÊNCIAS, 1841).

As equipes da demarcação trabalharam ao longo do rio Peperi-Guaçu até o dia 06 de abril do mesmo ano, agora sob influência de chuvas mais torrenciais, responsável pela modificação dos aspectos hídricos do mesmo. Nesse período, além do rio Peperi-Guaçu, cartografaram seu maior afluente, o rio Pepiry Mini, atual rio das Flores. Após encerrarem os trabalhos de demarcação do rio Peperi-Guaçu, partiram para o mapeamento do rio Santo Antônio, afluente do rio Iguaçu e que, segundo o Tratado de Madri, também se constituía em limite de fronteira entre as duas coroas, conforme o Artigo V. Embora no referido tratado, o rio Santo Antônio não tivesse sido nominado, nos diários de registros da demarcação e mesmo na carta gerada desse trabalho, o mesmo é constantemente referido sob tal denominação (ANGELIZ, 1836; ACADEMIA REAL DAS SCIÊNCIAS, 1841).

Dois marcos geográficos foram deixados durante os trabalhos de demarcação e mapeamento do rio Peperi-Guaçu. O primeiro, à margem direita do rio, na sua desembocadura, consistiu no desmatamento de pequena área, em que no centro deixou-se apenas uma árvore alta, na qual se fixou uma cruz de madeira com as inscrições "R.F. anno de 1759". O segundo marco foi também feito à margem direita do rio, a montante da desembocadura do rio das Flores. De mesma maneira, consistiu no desmatamento de pequena área com a manutenção de uma árvore alta em seu centro, onde no lado voltado para norte gravou-se uma cruz, sem inscrições. Atualmente, tais marcos não mais existem nos referidos locais (SOUSA, 1939; MARTÍN-MERÁS, 2007).

Como resultado dessa expedição da Segunda Partida, foi confeccionado o Mapa da Demarcação, de autoria de Manoel Pacheco de Christo, publicado no ano seguinte à expedição, em 1760, constituindo-se no primeiro registro cartográfico oficial do rio Peperi-Guaçu (ANGELIZ, 1836).

\section{CONSIDERAÇÕES FINAIS}

A produção cartográfica jesuítica se constituiu em fator preponderante na caracterização do rio Peperi-Guaçu. Embora o mesmo fosse grafado sob diferentes maneiras, em mapas desde o século XVII (Pequiri, Pepiri ou Pipiry), já era possível ver a importância estratégica dess e afluente por facilitar a conexão entre as bacias hidrográficas dos rios Uruguai (ocupação dos Sete Povos) e Iguaçu (ocupação do Guayrá).

Os estudos dos diários da Segunda Partida Demarcatória, escritos pelos portugueses, mostraram que o rio Peperi-Guaçu era utilizado como caminho natural entre os povos indígenas que habitavam a 
região oeste dos três estados do sul do Brasil, antes da chegada dos europeus à região. Posteriormente, esse caminho natural foi utilizado durante a implantação e a consolidação das províncias missioneiras que se estabeleceram nos atuais estados do Paraná e do Rio Grande do Sul como rota de troca de produtos. Esse traçado foi elegido como fronteira natural dos territórios das coroas de Espanha e Portugal, na América do Sul.

Assim como o Peperi-Guaçu foi rota de integração entre as referidas províncias missioneiras, foi também rota de ocaso das mesmas. Esta rota teria se constituído em um dos vários trajetos utilizados por bandeirantes paulistas durante os processos de aprisionamento de indígenas. Embora originalmente registrado em mapas e cartas elaborados inicialmente por padres jesuítas e, posteriormente, incluídos em documentos oficiais para a elaboração do Tratado de Madri (1750), a área abarcada pela bacia do rio nunca foi efetivamente mapeada e cartografada. Ao longo das várias representações cartográficas, as quais foram mostradas neste artigo: Paraquaria, "Paraquaria cum adjacentibus", Mapa das Cortes e Mapa da Demarcação, percebe-se que o traçado desses mapas variava, sendo que somente no último é possível perceber a representação mais próxima daquela observada na cartografia atual.

O estabelecimento do rio Peperi-Guaçu como limite de fronteiras entre as duas coroas na bacia do Prata ampliou a área de ocupação portuguesa no atual estado catarinense que, anteriormente ao Tratado de Madri, estava restrita à porção litorânea, desde a baía da Babitonga, a norte, até o atual município de Laguna, a sul. Embora a preocupação, durante todo esse período, em se delimitar a linha fronteiriça no extremo oeste catarinense, não houve de imediato a intenção em ocupar a área principalmente por parte de Portugal, fato esse que seria somente observado a partir de início do século XX.

\section{REFERÊNCIAS}

ACADEMIA REAL DAS SCIENCIAS. Colleccão de noticias para a Historia e Geografia das nações ultramarinas que vivem nos domínios portuguezes ou lhes são visinhas. Lisboa: Tipografia da Academia Real das Sciencias, 1841. $7 \mathrm{v}$.

ALCALÁ, L.E. Fundaciones jesuíticas em Iberoamérica. Madrid: El Viso, 2002.

ALMEIDA, E.M. Livro de registro do Tratado de Santo Ildefonso (Volumes I, II, III) - 1777 a 1793: Edição de textos e estudo da pontuação. Dissertação (Mestrado em Letras) - Cuiabá: UFMT. 2005.

ÁLVAREZ, B.C. Las misiones de los padres jesuitas en Latinoamérica (1606-1767). La Razón Historica, v. 27, p. 146-185, 2014.

ANGELIZ, P. Reconocimiento del Rio Pepiri-Guazu, por D. Jose Maria Cabrer, coronel de Ingenieros, segundo comissário y geografo de la Segunda Partida Demarcadora, extractado de su diario inédito. Buenos Aires: Imprenta del Estado, 1836.

ARANHA, B.P.L. De Buenos Aires a Misiones: civilização e barbarie nos relatos de viagens realizadas à terra do mate (1882-1889). Dissertação (Mestrado em Integração da América Latina São Paulo: USP, 2014.

BARCELOS, A.H.F. Expedições Jesuíticas e cartografia americana: séculos XVII e XVIII. In: SIMPÓSIO IBEROAMERICANO DE HISTÓRIA DA CARTOGRAFIA, 3., 2010, São Paulo. Anais... São Paulo: USP, 2010. p. 5-15.

BERTO, C. Milagre, retórica e conflitos políticos. In: SIMPÓSIO NACIONAL DE HISTÓRIA, 26., São Paulo. Anais... São Paulo: USP, 2011. p. 7-25.

BIBLIOTECA DIGITAL LUSO-BRASILEIRA. Mapa das Cortes. 1 mapa, color. Escala indeterminável. Disponível em: https://bndigital.bn.gov.br/artigos/mapa-das-cortes/. Acesso em: 21 maio 2018.

Mappa da demarcação de s. m. f. e c. no anno de 1759, a seg.da partida da boca do rio ibicuy, seguindo o curço dos rios uruguay, piriry s. ant iguaçu, e paranã c. 1 mapa color. Escala indeterminável. Disponível em: http://bdllb.bn.gov.br/acervo/handle/123456789/21192. Acessado em 21 maio 2018.

Mapa paraquaria vulgo paraguay cum adjacentibus. 1 mapa, color. Escala indeterminável. Disponível em: https://bdlb.bn.gov.br/acervo/handle/20.500.12156.3/16524. Acesso em: 25 maio 2018. 
Mapa paraquaria provinciae cum adiacentibo novíssima descriptio. 1 mapa, color. Escala indeterminável. Disponível em: https://www.wdl.org/pt/item/2581/view/1/1/. Acessado em: 21 maio 2018.

CAPDEVILA, J. Comisarios inteligentes en la Plata y el Amazonas. Los deslindes hispanoportugueses de fronteras del siglo XVIII. In: Segovia, F; Nóvoa, M. (coord.) Proyección en América de los ingenieros militares: Siglo XVIII. Madrid: Ministerio de Defensa, 2016. p. 289-312.

CHAVES, O.R. América portuguesa: do Tratado de Madri ao Tratado de Santo Ildefonso. Revista Territórios \& Fronteiras, v. 7, p. 218-234, 2014. https://doi.org/10.22228/rt-f.v7i2.352

CINTRA, J.P. O mapa das cortes e as fronteiras do Brasil. Boletim de Ciências Geodésicas, v. 18, p. 421-445, 2012. https://doi.org/10.1590/S1982-21702012000300005

CINTRA, J.P.; FURTADO, J.F. A Carte de l'Amérique Méridionale de Bourguignon D'Anville: eixo perspectivo de uma cartografia amazônica comparada. Revista Brasileira de História, v. 31, p. 273316, 2011. https://doi.org/10.1590/S0102-01882011000200015

COSTA, M.F. De Xarayes ao Pantanal: a cartografia de um mito geográfico. Revista do Instituto de Estudos Brasileiros, v. 45, p. 21-36, 2007. https://doi.org/10.11606/issn.2316-901X.v0i45p21-36

COSTA, M.F. Viajes en la frontera colonial: historias de una expedición de límites en la América Meridional. Anales del Museo de America, v. 16, n. 1, p. 113-126, 2009.

FANTIN, O.J. "Obedeciendo la orden de compendiar": registros de viagens de jesuítas nas cartas ânuas da Provícia Jesuítica do Paraguai (segunda metade do século XVII). Dissertação (Mestrado em História) - São Leopoldo: Unisinos. 2010.

FARINA, M.D.; OLIVEIRA, U.S. A coleção cartográfica do Tratado de Santo Ildefonso na Biblioteca Nacional. In: SIMPÓSIO BRASILEIRO DE CARTOGRAFIA HISTÓRICA, 3., 2016, Belo Horizonte. Resumos... Belo Horizonte: UFMG, 2016. p. 3-10.

FERRARI, M. As noções de fronteira em Geografia. Revista Perspectiva Geográfica, v. 9, p. 1-25, 2014.

FERREIRA, M.C. O Mapa das Cortes e o Tratado de Madri: a cartografia a serviço da diplomacia. Varia Historia, v. 23, p. 51-69, 2007. https://doi.org/10.1590/S0104-87752007000100004

FURLONG, G. Cartografía jesuítica del Río de la Plata. Buenos Aires: Instituto de Investigaciones Historicas, 1936. 2 v.

GOLIN, T. Cartografia da Guerra Guaranítica. In: SIMPÓSIO BRASILEIRO DE CARTOGRAFIA HISTÓRICA, 1., 2011, Paraty. Resumos... Paraty: UFMG, 2011. p. 1-16.

GONZÁLEZ, M.R. Los jesuítas en América. Utopía y realidad en las reducciones del Paraguay. In: TELLECHEA, J.I.; GONZÁLES, M.R.; PINEDO, I.; LÉCRIVAIN, P.; LACOUTURE, J.; LAMET, P.M.; VALERO, U.; LOWNEY, C.; BOLADO, A.A.; ORAÁ, J. (Coords.) Jesuítas: uma misión, un proyecto. Bilbao: Universidad de Deusto, 2007. p. 31-58.

MACHADO, L.O. Limites e fronteiras da alta diplomacia aos circuitos da ilegalidade. Revista Território, v. 5, p. 7-23, 2000.

MAEDER, E. De las missiones del Paraguay a los estados nacionales: configuración y disolución de una región histórica. In: GADELHA, R. Missões Guaranis: impactos na sociedade contemporânea. São Paulo: EDUC, 1999, p. 113-130.

MARTíN-MERÁS, L. Fondos cartográficos y documentales de la Comisión de Límites de Brasil en el siglo XVIII em el Museo Naval de Madrid. Terra Brasilis (Nova Série), v. 7, p. 1-82, 2007. https://doi.org/10.4000/terrabrasilis.402

MORAN, A.N.B. El piloto Andrés de Oyarvide y su labor en el Río de La Plata. Itsas Memoria, v. 6, p. 747-762, 2009.

OLIVEIRA, C. Dicionário de Cartografia. Rio de Janeiro: IBGE, 1983.

PEREIRA, M.A.F.C.G. Obras do Barão do Rio Branco I: questões de limites República Argentina. Brasília: FUNAG, 2012.

RIO-BRANCO, M.P. Alexandre de Gusmão e o Tratado de 1750. Brasília: FUNAG, 2010. 
SEGARRA, E.M. Frontera y límites. Nuestra Tierra, v. 42, p. 3-60, 1969.

SOUSA, O.T. Tratado de Madrid, 13 de janeiro de 1750. Colecção documentos brasileiros, v. 19, p. 1-10, 1939.

TAUNAY, A.E. História das bandeiras paulistas. São Paulo: Melhoramentos,1951. 2 v. https://doi.org/10.11606/issn.2316-9141.v2i6p440-441

XAVIER, N.R. A representação cartográfica da Província Jesuítica do Paraguai no século XVIII. In: CONGRESSO INTERNACIONAL DE HISTÓRIA, 5., Maringá, 2011. Resumos... Maringá, UEM, 2011. p. 15-24. https://doi.org/10.4025/5cih.pphuem.1617

Recebido em: 15/08/2019

Aceito para publicação em: 12/02/2020 